\title{
Molecular Detection of Mutations within the Quinolone Resistance-Determining Regions in Non Typhoidal Salmonella Isolates from Malaysia
}

\author{
Fadzilah Mohd-Nor ${ }^{1,2}$, Noor Aini Abu-Bakar ${ }^{1}$, Norzilawati Mohd-Isa1, Zubaidah A. Wahab ${ }^{3}$, \\ Zaini Mohd-Zain 1,2
}

${ }^{1}$ Microbiology Discipline, Faculty of Medicine, UniversitiTeknologi MARA, Sg. Buloh Campus, Jalan Hospital, Sg. Buloh, Selangor, Malaysia

${ }^{2}$ Community of Research (CoRE) of Health \& Wellbeing, UniversitiTeknologi MARA, Shah Alam, Selangor, Malaysia

${ }^{3}$ Microbiology Unit, Department of Pathology, Hospital Sg. Buloh, Sg. Buloh, Selangor, Malaysia

Email:`fadzi456@salam.uitm.edu.my,nooraini1487@gmail.com,zie_sa@yahoo.com,dr_zubaidah@moh.gov.my,

zainimz@salam.uitm.edu.my

How to cite this paper: Mohd-Nor, F., Abu- Bakar, N.A., Mohd-Isa, N., Wahab, Z.A. and Mohd-Zain, Z. (2017) Molecular Detection of Mutations within the Quinolone Resistance-Determining Regions in Non Typhoidal Salmonella Isolates from Malaysia. Health, 9, 640-648.

https://doi.org/10.4236/health.2017.94045

Received: November 1, 2016

Accepted: April 15, 2017

Published: April 18, 2017

Copyright $\odot 2017$ by authors and Scientific Research Publishing Inc. This work is licensed under the Creative Commons Attribution International License (CC BY 4.0).

http://creativecommons.org/licenses/by/4.0/

\begin{abstract}
Introduction: The efficacy of chemotherapy in bacteraemia caused by nontyphoidal Salmonella (NTS) is compromised by antibiotic resistance. Objective: This study was undertaken to describe the mechanism of resistance among clinical NTS isolates. Materials \& Methodology: Thirty of NTS were isolated from blood $(\mathrm{n}=19)$, stool $(\mathrm{n}=10)$ and bronchioalveolar lavage (BAL; $\mathrm{n}=1$ ) respectively. These isolates were tested for susceptibility testing by disc diffusion method against ampicillin, gentamicin, tetracycline, co-trimoxazole, nalidixic acid, ciprofloxacin and ceftriaxone. Epsilometer tests (E-test) for nalidixic acid and ciprofloxacin were performed for nalidixic acid resistant isolates by disc diffusion method. DNA sequencing was carried out on six of the nalidixic acid resistant Salmonella Enteritidis isolates to identify mutations within quinolones resistance determining regions (QRDR) of $g y r A, g y r B$, parC and parE genes. Results: Resistance rates of NTS isolates from blood, stool, and BAL were respectively $37 \%, 20 \%$ and $0 \%$ for ampicillin, $79 \%, 40 \%$ and $0 \%$ for tetracycline, $32 \%, 40 \%$ and $0 \%$ for co-trimoxazole, $37 \%, 10 \%$ and $100 \%$ for nalidixic acid. Eight isolates were resistant to nalidixic acid and had exhibited reduced susceptibility towards ciprofloxacin by E-test. Mutation within QRDR was detected in gyrA gene $(\mathrm{n}=6$; Asp $47 \rightarrow$ His [3], Asp $51 \rightarrow$ Asn [1], Asp $73 \rightarrow$ Gly [1], and Gly $48 \rightarrow$ Asp [1]) and double mutation was detected in parE gene ( $\mathrm{n}=3$; Gly $48 \rightarrow$ Asp [3], Glu $82 \rightarrow$ Ser [3]). Out of six isolates, three isolates were found to have both $\operatorname{gr} A$ and $\operatorname{par} E$ gene mutations. Conclusions: There was no mutation observed in $\operatorname{gyr} B$ and $\operatorname{par} C$ gene. Muta-
\end{abstract}


tion in gyrA gene was sufficient to induce decreased susceptibility to ciprofloxacin. Variation in amino acid sequences are novel, while detection of other gene mutation was uncommon.

\section{Keywords}

Non-Typhoidal Salmonella, Quinolones Resistance-Determining Regions, Ciprofloxacin

\section{Introduction}

Antibiotics are used for the therapy of invasive diseases or complicated bacteraemia caused by non-typhoidal Salmonella (NTS). The prevalence of multidrug resistant NTS in adult patients has gradually increased in the last decade, making the treatment of invasive salmonellosis a clinical dilemma [1] [2] [3] [4] [5]. Fluoroquinolones is a broad-spectrum antimicrobial agent that inhibits DNA gyrase in susceptible organisms and promotes breakage of double-stranded DNA. It is highly effective in urinary tract infections, gonorrhoea, invasive gastrointestinal infections, intra-abdominal infections and lower respiratory tract infections in adults [6]. It is also widely used in agriculture and veterinary medicine [2] [7] [8] [9].

In principle there are four types of mechanism of antimicrobial resistance including inhibition of cell wall synthesis, inhibition of protein synthesis, inhibition of nucleic acid synthesis, and alteration of cell membrane function by which bacteria evade the action of antimicrobial agents. They work independently or in combination ranging from reduced susceptibility, which is not always detected by current antimicrobial susceptibility tests, to clinically relevant resistance. Resistance to quinolones is mainly mediated by chromosomal mutations which results to the target alteration of DNA gyrase and topoisomerase IV.

In Gram negative bacteria, the GyrA subunit of DNA gyrase is the most frequent primary target while topoisomerase IV are secondary target for quinolones. However, the contrary is true for Gram-positive bacteria [10] [11]. Point mutations most often occur within the highly conserved domain of the $\mathrm{N}$-terminus of the gyrA gene, also known as "quinolone resistance-determining region" (QRDR) [11] [12]. Most isolates resistant to nalidixic acid (NAL) have a single point mutation in the QRDR of gyr $A$, whilst resistance to ciprofloxacin is accomplished in isolates having double mutations in gyrA gene[12] [13].

Nalidixic aciddisc is used as "surrogate marker" to screen for reduced fluoroquinolone (FQ) susceptibility in Salmonella, as it has been shown that high resistance NAL is associated with reduced FQ susceptibility [4]. Nevertheless, the NAL screening may miss isolates that exhibit reduced FQ susceptibility by being susceptible or only displaying low-level resistance to nalidixic acid. Recent data have raised concern that NAL resistance may no longer be a reliable indicator for reduced ciprofloxacin (CIP) susceptibility as results of evolving Salmonella 
FQ resistance mechanisms. There are reports of NAL-susceptible isolates with reduced FQ susceptibility [14] [15] [16] with the phenotype appears to be mediated by different resistance mechanisms outside the gyrA gene.

Mutations in $\operatorname{gyr}_{r} B$ results in CIP minimum inhibitory concentrations (MICs) of $0.125-0.5 \mu \mathrm{g} / \mathrm{mL}$ and NAL MICs of $2-16 \mu \mathrm{g} / \mathrm{mL}$, both within the susceptible range [17]. Similarly, plasmid-mediated quinolone resistance (PMQR) determinants, $q n r$ and aac'-6-Ib-cr genes [18], are associated with modest NAL MIC elevations $(8-32 \mu \mathrm{g} / \mathrm{mL})$ and increased resistance to CIP [19] [20]. These PMQR are commonly found in Europe and Asia [21] [22].

Systematic epidemiological studies are required to determine the effect of reduced fluoroquinolone susceptibility on human health and its implications for treatment options. In vitro resistance to nalidixic acid isolates has been associated with reduced efficacy of fluoroquinolones in vivo [23].

This study aims to identify the mechanism of chromosomal mutations involved in QRDR that leads to decreased CIP susceptibility among NTS isolates in Malaysia. Nevertheless, this information will serve as reference and surveillance tool for antibiotic resistance pattern that can be used at regional and international level. This could improve options for empirical antibiotic therapy and consequently, patient outcomes.

\section{Materials and Methods}

Salmonella strains: A total number of 30 NTS isolates belongs to 28 patients were obtained from December 2011 to December 2012 from Hospital Sg. Buloh, Selangor, Malaysia for detailed investigation. The NTS isolates were collected and identified from blood, stool, and bronchioalveolar lavage (BAL) culture. The isolates were further serotyped based on Kauffmann-White scheme and confirmed to be NTS. Those that were resistant to nalidixic acid were species identified by polymerase chain reaction (PCR).

Antimicrobial susceptibility testing: Susceptibility testing of the NTS isolates was performed towards six antimicrobial agents including ampicillin, tetracycline, gentamicin, nalidixic acid, ciprofloxacin and ceftriaxone by disc diffusion (Beckton Dickinson, USA) method. The Epsilometer test (E-test) (BioMeriaux, France) for NAL and CIP were carried out for NAL resistant NTS isolate to determine MIC. The MIC determination was performed according to Clinical and Laboratory Standards Institute (CLSI), 2015 [24]. A NAL resistance is defined as a MIC of $\geq 32 \mu \mathrm{g} / \mathrm{ml}$ while reduced susceptibility to CIP is defined as a MIC of $\geq 0.125 \mu \mathrm{g} / \mathrm{ml}$ as previously described [13]. All NAL-resistant isolates determined by E-test were examined for the mutation by PCR and sequence analysis.

Detection of target gene mutations: Polymerase chain reaction was used to amplify and screen the QRDR of gyrA, gyrB, parC and parE genes as previously described [25] using established primers [26]. Bands of the correct size were excised and purified using Wizard SV Gel and PCR Clean-Up System kit (Promega, Madison, USA) and were sent to Institute of Medical Molecular Bio- 
technology (IMMB), Faculty of Medicine, Universiti Teknologi MARA (Selangor, Malaysia) for sequencing. The sequences that were obtained were assembled using BioLign version 2.0.9 (http: //en.bio-soft.net/dna/BioLign.html) and the genes were compared to the respective genes in the Genbank using BLAST tool (http: //www.ncbi.nlm.nih.gov).

\section{Results}

The 30 NTS isolates were obtained from three types of specimen including blood $(\mathrm{n}=19)$, stool $(\mathrm{n}=10)$ and BAL $(\mathrm{n}=1)$. Antimicrobial susceptibility testing by disc diffusion method revealed that NTS isolates from blood were resistant to ampicillin $(36.8 \%)$, tetracycline $(79.0 \%)$, co-trimoxazole $(31.6 \%)$, and nalidixic acid (36.8\%), while, $20.0 \%$ of NTS isolates from stool were resistant to ampicillin, $40.0 \%$ to tetracycline, $40.0 \%$ to co-trimoxazole and $10 \%$ to NAL. Non-typhoidal Salmonella isolate from bronchioalveolar lavage (BAL) was resistant to NAL and demonstrated susceptibility to other antibiotics. All NTS isolates from blood, stool, and BAL culture were susceptible to gentamicin, CIP, and ceftriaxone respectively.

The MIC of the eight NTS isolates by E-test revealed 75\% (blood: 83.3\% [5/6], BAL: $16.7 \%$ [1/6]) of NTS isolates were resistant to NAL, and $87.5 \%(n=7 / 8)$ of isolates demonstrated reduced susceptibility to CIP. Of eight NTS isolates that were subjected to E-test, seven were serotyped as Salmonella enterica Serovar Enteritidis and remaining as Salmonella enterica Serovar Corvallis. All the $S$. Enteritidis were resistant to NAL and were isolated from the blood.

Sequence analysis revealed that six out of seven $S$. Enteritidis isolates had amino acid substitutions as a result of point mutations within QRDR of the $g y r A$ gene. In three isolates, the aspartic acid at codon 47 was replaced with histidine (Asp $47 \rightarrow$ His), while two other isolates had their aspartic acid at codon 51 and 73 substituted with asparagine (Asp $51 \rightarrow$ Asn) and glycine (Asp $73 \rightarrow$ Gly) residue respectively. In the remaining one isolate, glycine at codon 48 was resulted into aspartic acid substitution (Gly $48 \rightarrow$ Asp).

In addition to it, amino acid substitutions were also observed due to a single base pair (T) insertion in parE gene from three isolates of $S$. Enteritidis. In all three isolates, glutamine at codon 81 was resulted into leucine substitution (Gln $81 \rightarrow$ Leu) with glutamate at codon 82 was replaced by serine (Glu $82 \rightarrow$ Ser). Hence, all the six isolates of $S$. Enteritidis had point mutations at $g y r A$ gene, and three isolates had mutation in both $g y r A$ and $\operatorname{parE}$ gene. However, none of the $S$. Enteritidis isolates had mutation detected at $\operatorname{gyr} B$ and $\operatorname{par} C$ gene. A NAL MIC elevations $(16 \mu \mathrm{g} / \mathrm{mL})$ with increased resistance to CIP $(0.5 \mu \mathrm{g} / \mathrm{mL} ; 0.75 \mu \mathrm{g} / \mathrm{mL})$ were detected in the other remaining isolates of $S$. Enteritidis and $S$. Corvallis. The results are shown in Table 1 .

\section{Discussion}

In recent years, the proportion of NTS strains with reduced FQ susceptibility has increased in many countries including the United States, United Kingdom and 
Table 1. Determination of MIC and detection of target gene mutations.

\begin{tabular}{|c|c|c|c|c|c|c|}
\hline \multirow[b]{2}{*}{ Isolates } & \multicolumn{2}{|c|}{ MIC ( $\mu \mathrm{g} / \mathrm{ml})$} & \multicolumn{4}{|c|}{ QRDR mutation } \\
\hline & NAL & CIP & $g y r A$ & $g y r B$ & $\operatorname{par} C$ & parE \\
\hline 3012005267 & 256 & 0.25 & Gly 48 to Asp & - & - & \\
\hline 3012006354 & 256 & 0.125 & Asp 47 to His & - & - & $\begin{array}{l}\text { Gln } 81 \text { to Leu } \\
\text { Glu } 82 \text { to Ser }\end{array}$ \\
\hline 3012037286 & 16 & 0.75 & - & - & - & \\
\hline 3012037287 & 16 & 0.5 & - & - & - & \\
\hline 3012038240 & 512 & 0.94 & Asp 73 to Gly & - & - & $\begin{array}{l}\text { Gln } 81 \text { to Leu } \\
\text { Glu } 82 \text { to Ser }\end{array}$ \\
\hline 3012039138 & 512 & 0.125 & Asp 47 to His & - & - & \\
\hline 3012034257 & 512 & 0.125 & Asp 51 to Asn & - & - & \\
\hline 3012058507 & 512 & 0.125 & Asp 47 to $\mathrm{His}$ & - & - & $\begin{array}{l}\text { Gln } 81 \text { to Leu } \\
\text { Glu } 82 \text { to Ser }\end{array}$ \\
\hline
\end{tabular}

NAL: nalidixic acid; CIP: ciprofloxacin. Asp: Aspartate, Asn: Asparagine, Gln: Glutamine, Glu: Glutamate, Gly: Glycine, His: Histidine, Leu: Leucine, Ser: Serine -: Mutation was not detected.

Southeast Asia [1] [2] [4] [27] [28]. This situation is worrisome, as FQ is the first line antibiotic to be administered in the treatment of invasive disease caused by NTS. Over the past 7 to 12 years, there has been a seven-fold significant increase in non-typhi Salmonella enterica isolates that are resistant to NAL, and $91 \%$ of these isolates showed decreased susceptibility to CIP [18]. Additionally, reports have documented poor FQ treatment outcomes for systemic infections caused by NAL-resistant and reduced CIP susceptibility isolates of NTS [24].

In our study, $75 \%$ of NTS isolates were resistant to NAL, and $87.5 \%$ of these isolates exhibited reduced susceptibility to CIP, with MIC CIP ranges from 0.125 to $0.94 \mu \mathrm{g} / \mathrm{mL}$. These findings correspond with previous reports [1] [3] [4] [18] [19], and reveal the increasing resistance of NAL with decreased susceptibility to CIP amongst NTS isolates in Malaysia. The NTS isolates were resistant to common antimicrobials (ampicillin and trimethoprim-sulfamethoxazole) and this concurs with previous related reports that described high resistance rate of NTS isolates to ampicillin, chloramphenicol and trimetophrim-sulfamethoxazole [23], [29].

Point mutations were identified on the DNA-binding surface of the enzyme near the putative active site tyrosine 122 in $\mathrm{N}$ terminal region of the GyrA [12]. Previous studies reported that mutations in gyrA QRDR are most commonly found at codons Asp 87 and Ser 83 [25] [30] [31] [32], leading to amino acid substitution associated with the NAL resistance in Salmonella strains. However, our findings are unique as novel mutations were observed at codons Asp 47, Asp 51, Asp 73 and Gly 48.

Mutations within QRDR of parC and parE genes were rarely detected and reported among Salmonella isolates [25] [31] [32]. The finding of double mutations in $\operatorname{parE}$ gene in this study are remarkable, and may be associated with higher level of FQ resistance [30] [31]. In addition to it, parE gene mutations were identified in three $S$. Enteritidis isolates that were having gyrA gene muta- 
tions too. The isolates used in this study were resistant to nalidixic acid but susceptible to ciprofloxacin. These findings are in parallel to previous reports which suggested that multiple mutations are required for higher level of FQ resistance, while single mutation is important for resistance to quinolones [23] [31] [32].

There is a possibility that an isolate of $S$. Enteritidis and $S$. Corvallis are harbouring the PMQR determinants, $q n r$ and $a a c-6$ - $I b-c r$ genes, as these isolates were susceptible to NAL with MIC: $16 \mu \mathrm{g} / \mathrm{mL}$, and increased resistance to CIP $(0.5 \mu \mathrm{g} / \mathrm{mL} ; 0.75 \mu \mathrm{g} / \mathrm{mL})$. However, another study needs to be carried out to identify and confirm the presence of PMQR determinant genes.

The data of this study impart the rate of nalidixic acid resistance and reduced ciprofloxacin susceptibility among non-typhoidal Salmonella clinical isolates in Malaysia. Novel amino acid exchanges found in this collection of isolates provides better understanding towards possible mechanisms that could be responsible for the nalidixic acid resistance and decreased ciprofloxacin susceptibility. Despite small number of $S$. Enteritidis isolates in this study, the results obtained would be an essential reference for epidemiological and public health purposes especially in Malaysia, as well as in Southeast Asia region. Indirectly, this information will be constructive in modifying and deescalating the initial antimicrobial treatment.

In conclusion, the rate of nalidixic acid resistance and reduced susceptibility to ciprofloxacin is considered high in Malaysia. The resistance of $S$. Enteritidis isolates were essentially caused by point mutations in gyrA and parE genes. Furthermore $S$. Enteritidis is the most frequently isolated serotype causing bacteraemia, as all resistant isolates were isolated from the blood culture. Therefore, regional surveillance of antimicrobial resistance among non-typhoidal Salmonella isolates collected from food, animals and humans need to be enhanced to improve the management of invasive bacteraemia, particularly caused by $S$. Enteritidis, and to mitigate the increasing resistance rate of flouroquinolones.

\section{Ethics Approval}

Ethics approval to conduct the study and review the data was obtained from Universiti Teknologi MARA (UiTM) Research Ethics Committee 600-RMI/ST/ DANA 5/3/Dst (343/2011).

\section{Conflict of Interest}

On behalf of all authors, the corresponding author states that there is no conflict of interest.

\section{Acknowledgements}

We thank Mr. Abu Thalhah from Institute of Medical \& Molecular Biotechnology (IMMB), Faculty of Medicine, Universiti Teknologi MARA, Malaysia for the excellent technical support and Research Management Institute for Dana Kecemerlangan Grant, Universiti Teknologi MARA, 600-RMI/ST/ DANA 5/3/Dst $(343 / 2011)$. 


\section{References}

[1] Crump, J.A., Medalla, F.M., Joyce, K.W., Krueger, A.L., Hoekstra, R.M., Whichard, J.M., et al. (2011) Antimicrobial Resistance among Invasive Nontyphoidal Salmonella enterica Isolates in the United States: National Antimicrobial Resistance Monitoring System, 1996 to 2007. Antimicrobial Agents and Chemotherapy, 55, 1148-1154. https://doi.org/10.1128/AAC.01333-10

[2] Rayamajhi, N., Jung, B.Y., Cha, S.B., Shin, MK., Kim, A., Kang, M.S., et al. (2010) Antibiotic Resistance Patterns and Detection of bla $a_{\text {DHA-1 }}$ in Salmonella Species Isolates from Chicken Farms in South Korea. Applied and Environmental Microbiology, 76, 4760-4764. https://doi.org/10.1128/AEM.02536-09

[3] Kariuki, S., Revathi, G., Kariuki, N., Muyodi, J., Mwituria, J., et al. (2005) Increasing Prevalence of Multidrug-Resistant Non-Typhoidal Salmonella in Kenya, 1994-2003. International Journal of Antimicrobial Agents, 25, 38-43. https://doi.org/10.1016/j.ijantimicag.2004.08.015

[4] Su, L.H., Chiu, C.H., Chu, C. and Ou, J.T. (2004) Antimicrobial Resistance in Nontyphoid Salmonella Serotypes: A Global Challenge. Clinical Infectious Diseases, 39, 546-551. https://doi.org/10.1086/422726

[5] Piddock, L.J. (2002) Flouroquinolone Resistance in Salmonella Serovars Isolated from Humans and Food Animals. FEMS Microbiology Reviews, 26, 3-16. https://doi.org/10.1111/j.1574-6976.2002.tb00596.x

[6] Medscape (2015) Fluoroquinolones. http://reference.medscape.com/drug/cipro-xr-ciprofloxacin-342530\#0

[7] Kudaka, J., Itokazu, K., Taira, K., Iwai, A., Kondo, M. and Susa, T. (2006) Characterization of Salmonella in Okinawa, Japan. Japanese Journal of Infectious Diseases, 59, 15-19.

[8] Bager, F. and Helmuth, R. (2001) Epidemiology of Resistance to Quinolones in Salmonella. Veterinary Research, 32, 285-290.

https://doi.org/10.1051/vetres:2001125

[9] Angulo, F.J., Johnson, K.R., Tauxe, T.V. and Cohen, M.L. (2000) Origins and Consequences of Antimicrobial-Resistant Nontyphoidal Salmonella: Implications for the Use of Fluoroquinolones in Food Animals. Microbial Drug Resistance, 6, 77-83. https://doi.org/10.1089/mdr.2000.6.77

[10] Jacoby, G.A. (2005) Mechanisms of Resistance to Quinolones. Clinical Infectious Diseases, 41, S120-S126. https://doi.org/10.1086/428052

[11] Li, X. (2005) Quinolone Resistance in Bacteria: Emphasis on Plasmid-Mediated Mechanisms. International Journal of Antimicrobial Agents, 25, 453-463. https://doi.org/10.1016/j.ijantimicag.2005.04.002

[12] Piddock, L.J. (1999) Mechanisms of Fluoroquinolone Resistance: An Update 19941998. Drugs, 58, 11-18. https://doi.org/10.2165/00003495-199958002-00003

[13] Oteo, J., Aracil, B., Alos, J.L. and Gomez-Garces, J.L. (2000) High Rate Resistance to Nalidixic Acid in Salmonella enterica: Its Role as a Marker of Resistance to Fluoroquinoles. Clinical Microbiology and Infection, 6, 273-276. https://doi.org/10.1046/j.1469-0691.2000.00058-3.x

[14] Hakanen, A.J., Lindgren, M., Huovinen, P., Jalava, J., Siitonen, A. and Kotilainen, P. (2005) New Quinolone Resistance Phenomenon in Salmonella enterica: Nalidixic Acid-Susceptible Isolates with Reduced Fluoroquinolone Susceptibility. Journal of Clinical Microbiology, 43, 5775-5778. https://doi.org/10.1128/jcm.43.11.5775-5778.2005

[15] Cooke, F.J., Wain, J. and Threlfall, E.J. (2006) Fluoroquinolone Resistance in Sal- 
monella Typhi. BMJ, 333, 353-354. https://doi.org/10.1136/bmj.333.7563.353-b

[16] Sjolund-Karlsson, M., Folster, J.P., Pecic, G., Joyce, K., Medalla, F., Rickect, R., et al. (2009) Emergence of Plasmid Mediated Quinolone Resistance among Non-Typhi Salmonella enterica Isolates from Humans in the United States. Antimicrobial Agents and Chemotherapy, 53, 2142-2144. https://doi.org/10.1128/AAC.01288-08

[17] Accou-Demartin, M., Gaborieau, V., Song, Y., Roumagnac, P., Marchou, B., Achtman, M., et al. (2011) Salmonella enterica Serotype Typhi with Nonclassical Quinolone Resistance Phenotype. Emerging Infectious Diseases, 17, 1091-1094. https://doi.org/10.3201/eid/1706.101242

[18] Poirel, L., Cattoir, V. and Nordmann, P. (2008) Is Plasmid-Mediated Quinolone Resistance a Clinically Significant Problem? Clinical Microbiology and Infection, 14, 295-297. https://doi.org/10.1111/j.1469-0691.2007.01930.x

[19] Hopkins, K.L., Day, M. and Threlfall, E.J. (2008) Plasmid-Mediated Quinolone Resistance in Salmonella enterica, United Kingdom. Emerging Infectious Diseases, 14, 340-342. https://doi.org/10.3201/eid1402.070573

[20] Cavaco, L.M., Hasman, H., Xia, S. and Aarestrup, F.M. (2009) qnrD, a Novel Gene Conferring Transferable Quinolone Resistance in Salmonella enterica Serovar Kentucky and Bovismorbificans Strains of Human Origin. Antimicrobial Agents and Chemotherapy, 53, 603-608. https://doi.org/10.1128/AAC.00997-08

[21] Song, Y., Roumagnac, P., Weill, F.X., Wain, J., Dolecek, C., Mazzoni, J.C., et al. (2010) A Multiplex Single Nucleotide Polymorphism Typing Assay for Detecting Mutations That Result in Decreased Fluoroquinolone Susceptibility in Salmonella enterica Serovars Typhi and Paratyphi A. Journal of Antimicrobial Chemotherapy, 65, 1631-1641. https://doi.org/10.1093/jac/dkq175

[22] Yu, F., Chen, Q., Yu, X., Pan, J., Li, Q., Yang, L., et al. (2011) High Prevalence of Plasmid-Mediated Quinolone Resistance Determinant aac(6')-Ib-cr amongst Salmonella enterica Serotype Typhimurium Isolates from Hospitalised Paediatric $\mathrm{Pa}$ tients with Diarrhoea in China. International Journal of Antimicrobial Agents, 37, 152-155. https://doi.org/10.1016/j.ijantimicag.2010.10.021

[23] Humphries, M.R., Fang, C.F., Aarestrup, M.F. and Hindler, A.J. (2012) In Vitro Susceptibility Testing of Fluoroquinolone Activity against Salmonella: Recent Changes to CLSI Standards. Clinical Infectious Diseases, 55, 1107-1113. https://doi.org/10.1093/cid/cis600

[24] (2015) Zone Diameter and Minimal Inhibitory Concentration Interpretive Standards for Enterobacteriaceae in Performance Standards for Antimicrobial Susceptibility Testing, Twenty-Fifth Informational Supplement. M100-S25 Clinical and Laboratory Standards Institute, 44-50.

[25] Lunn, A.D., Fabrega, A., Sanchez-Cespedes, J. and Villa, J. (2010) Prevalence of Mechanisms Decreasing Quinolone-Susceptibility among Salmonella spp. Clinical Isolates. International Microbiology, 13, 15-20.

[26] Giraud, E., Brisabois, A., Martel, J.L. and Chaslus-Dancla, E. (1999) Comparative Studies of Mutations in Animal Isolates and Experimental in Vitro and in VivoSelected Mutants of Salmonella spp. Antimicrobial Agents and Chemotherapy, 43, 2131-2137.

[27] Murray, A., Coia, J.E., Mather, H. and Brown, D.J. (2005) Ciprofloxacin Resistance in Non-Typhoidal Salmonella Isolates in Scotland, 1993-2003. Journal of Antimicrobial Chemotherapy, 56, 110-114. https://doi.org/10.1093/jac/dki164

[28] Jennifer, E.S., Kathryn, G., Timothy, J.B., Felicita, M., Tom, M.C. and Frederick, J.A. (2007) Increase in Nalidixic Acid Resistance among Non-Typhi Salmonella enterica Isolates in the United States from 1996-2003. Antimicrobial Agents and 
Chemotherapy, 51, 195-197. https://doi.org/10.1128/AAC.00222-06

[29] Centers for Disease Control and Prevention (2013) National Antimicrobial Resistance Monitoring System for Enteric Bacteria (NARMS): 2013 Annual Report. U.S. Department of Health and Human Services, CDC, Atlanta.

[30] Ngoi, S.T. and Thong, K.L. (2014) High Resolution Melting Analysis for Rapid Mutation Screening in Gyrase and Topoisomerase IV Genes in Quinolone-Resistant Salmonella enterica. BioMed Research International, 2014, Article ID: 718084. https://doi.org/10.1155/2014/718084

[31] Hopkins, K.L., Davies, R.H. and Threlfall, E.J. (2005) Mechanisms of Quinolone Resistance in Escherichia coli and Salmonella: Recent Developments. International Journal of Antimicrobial Agents, 25, 358-373. https://doi.org/10.1016/j.ijantimicag.2005.02.006

[32] Kim, K.Y., Park, J.H., Kwak, H.S. and Woo, G.J. (2011) Characterization of the Quinolone Resistance Mechanism in Foodborne Salmonella isolates with High Nalidixic Acid Resistance. International Journal of Food Microbiology, 146, 52-56.

\section{Submit or recommend next manuscript to SCIRP and we will provide best} service for you:

Accepting pre-submission inquiries through Email, Facebook, LinkedIn, Twitter, etc. A wide selection of journals (inclusive of 9 subjects, more than 200 journals)

Providing 24-hour high-quality service

User-friendly online submission system

Fair and swift peer-review system

Efficient typesetting and proofreading procedure

Display of the result of downloads and visits, as well as the number of cited articles

Maximum dissemination of your research work

Submit your manuscript at: http://papersubmission.scirp.org/

Or contact health@scirp.org 